1 Danowski TS, Winkler AW, Elkinton JR. Biochemical and hemodynamic changes following the subcutaneous injection of glucose solution. $f$ Clin Invest 1947;26:887.

2 Charlton AJ. Cardiac arrest during transurethral prostatectom after absorption of 1.5\% glycine. Anaesthesia 1980;35:804.

3 Nesbit RM, Glickman SI. The use of glycine as an irrigating medium during transurethral resection. F Urol 1948;59:1212.

4 Norris TH, Aasheim GM. Sherrard DJ, Trennan JA. Symptomatology, patho-phvsiology and treatment of transurethr resection of the prostate syndrome. Br J Urol 1973;45:420-7.

5 Bird D, Slade N, Feneley RCL. Intravascular complications of transurethral resection of the prostate. Br f Urol 1982;54 564-5.

6 Sellevold $\mathrm{O}$, Breivik H, Tveter K. Changes in oncotic pressure, osmolality and electrolytes following transurethral resection the prostate using glycine as irrigating solution. Scand $\mathcal{f}$ Urol Nephrol 1983;17:31-6.

SIR,--The prominence accorded to the recent article by Dr John F Sinclair and his associates (14 September, $\mathrm{p}$ 691) concerning a single case of percutaneous nephrolithotomy with ultrasonic lithotripsy and the absorption of glycine into the circulation is liable to mislead readers about the safety of the technique. More than 1000 cases of percutaneous nephrolithotomy have now been carried out in London alone; the technique has been shown to carry a lower morbidity and mortality and is as effective as conventional nephrolithotomy. It is also very economical. ${ }^{12}$

Saline is the preferred irrigant for all upper tract endoscopy whether percutaneous or ureteroscopic. ${ }^{3-6}$ The only indication for the use of glycine is the use of diathermy, when the glycine irrigation period should be kept to an absolute minimum.

The use of physiological solutions $(0.9 \%$ saline or Ringer lactate solution) will not in itself preven a transurethral resection syndrome, which we have seen on two occasions, once during a percutaneou nephrolithotomy and once during a difficult bilateral percutaneous pyelolysis. Both these cases occurred during the early part of our series. By adopting the following rules no further cases have been seen.

(1) Induce a peroperative diuresis (with frusemide or mannitol). (2) Ensure that the irrigant is at body temparature, as cooling of the patient to $31^{\circ} \mathrm{C}$ has been seen in some patients when fluid at room temperature was used. (3) The irrigant heigh should be kept below $80 \mathrm{~cm}$. This, combined with the Amplatz open drainage system, will prevent intrarenal pressure surges. A similar effect can be achieved by using a continuous flow operating nephroscope. (4) The continuous assessment of input and output of irrigant is essential. If negative balance is recorded the procedure must be terminated immediately and resumed after 48-72 hours. (5) Complex stone manipulation or a one stage procedure should be avoided if there is any sign of damage to the renal pelvis. (6) The overall time for endoscopy should not be more than two hours. It is safer to place a nephrostomy tube and continue on a second occasion at an interval of few days if the procedure has not been completed in that time.

The transurethral syndrome is a rare complication and is avoidable by adhering to these basic principles. Percutaneous nephrolithotomy has been shown to be a safe and effective procedure for treating $85 \%$ of all renal stones and should replace open renal surgery for stone diseases.

R A MilleR H N WHITFIELD

Department of Urology,

St Bartholomew's Hospital,

London EC1A 7BE

1 Whitfield HN. Percutaneous nephrolithotomy. Br $\mathcal{J}$ Urol 1983; 55:609-12.

2 Wickham JEA, Miller RA, Kellett MJ. Percutaneous nephrolithotomy: results and cost effectiveness. $\mathrm{Br} \mathcal{F}$ Urol 1983; (suppl): 103-5

3 Marberger M, Stackl W. New developments in endoscopic surgery for ureteric calculi. Br $\mathcal{J}$ Urol 1983;(suppl) :34-40.
4 Segura JW. Endourology. Br f Urol 1984;132: 1079-84. Clayman RV, Castaneda-Zuriga W, eds. Techniques in endourology. Minnesota: Clayman, 1984:258-9.

6 Miller RA, Payne S, Wickham JEA. Electrohydraulic nephrolithotripsy, a preferable alternative to ultrasonic lithotripsy? $B r$ f Urol 1984;56:589-98.

\section{Is the incidence of ectopic pregnancy rising?}

SIR,-We have recently noted a sharp rise in the incidence of ectopic pregnancy in this unit and wonder whether others have made similar observations.

In 1984 we delivered 1613 patients; there were seven ectopic pregnancies, which gives an ectopic rate of 1 in 230 deliveries. So far this year (August 1985) we have seen 23 ectopic pregnancies and during this period we have had 1081 deliveries. The ectopic rate is therefore 1 in 47 deliveries.

In reviewing various well known causal factor we have found only one which appears to have been of any importance-the increased incidence of pelvic inflammatory disease. Seventy per cent of ectopic pregnancies occurred in women over the age of 28 . However, 25 of the 30 women had eithe no children or only one child. Eight of those operated on had the tube conserved with a view to later reconstruction.

The incidence of ectopic pregnancy has been shown to be rising in America, Canada, and Sweden and we can expect a further rise here. Since most of these women will be interested in further pregnancies, we would suggest that greater emphasis be placed on conservation of the tube and later reconstruction.

\section{Michael Burke} Peter Dale

Maternity and Gynaecological Department,

North Tyneside General Hospital North Shields,

Tyne and Wear NE29 8NH

\section{Over the counter sale of topical} corticosteroids

Sir,-Professor Malcolm W Greaves now admit (27 July, p 276) he would "not support indiscriminate over the counter (OTC) sale of hydrocortisone. Why so if it is safe? The idea of "pharmacy control is a fallacy and will remain so. . . as long as advertising men and not the needs of the individual patient create and sustain demand for a product." The case against OTC hydrocortisone is $(a)$ there is no proof of need or efficacy; $(b)$ corticosteroid activity and toxicity are not dissociable; $(c)$ it is drug abuse not self medication.

Professor Greaves's use of $15 \mathrm{~g}$ as the amount of intment or cream which "would cover most of an adult body" is an abuse of the excellent paper he misquoted. ${ }^{2}$ The appropriate figure is not the averag quantity applied to patients by "trained operators" but the maximum that may be put on skin by self administration-115 g. Furthermore, the perineum from which absorption is particularly great, ${ }^{3}$ took seven times that predicted from surface area. His calculation used a mean percentage absorption from one early single dose study ${ }^{4}$ ignoring that the same workers showed that absorption increases with dose -for example, by four times-and with repeated applications ${ }^{6}-5-10$ fold. The suggested explanation that repeated application of hydrocortisone enhances its own absorption is, however, unacceptable: the likely explanation is that the early study quoted by Greaves $^{4}$ was an underestimate because using a single hydrocortisone application steady state equilibrium had not been achieved. There is a difference between quoting reports and understanding them, and Professor Greaves has failed to recognise the under estimate of these early studies where steady state kinetics were not used. Furthermore, Professor
Greaves ignores the otherwise excellent data of Feinblatt $e t a l,{ }^{7}$ who found up to $44 \%$ recovery from a single application to normal skin and $50 \%$ to chronic eczema. Nor does he appear to be aware of the $15 \%$ underestimate from unmeasured biliary excretion. Thus both quantities of hydrocortisone applied and absorbed could be as much as 10 times greater than that calculated from a limited and uncritical look at published reports.

Professor Greaves was "unable to find any reports of systemic toxicity due to topical hydrocortisone." Here are a few: fluid retention, ${ }^{7}$ stunted growth ${ }^{8}$ benign intracranial hypertension. ${ }^{9} \mathrm{He}$ dismisses toxic effects with a dated study of 19 patients ${ }^{10}$ which dismissed pustulation, hypertrichosis, weight gain, and hyper tension in some patients and used such gross indices of pituitary-adrenal function as eosinophil count. ${ }^{\prime \prime}$ Professor Greaves alleges that OTV hydrocortisone would be safe because of inactivation in the skin, although the paper he quotes allows no such conclusion. ${ }^{12}$ Only two subjects were studied and most of the work was done in one man: inactivation of hydrocortisone was found only in abdominal wall skin; there was little in facial skin and none in perineal skin. Nor was it shown at which doses rate of metabolism might be important, while in vivo studies, ${ }^{7}$ which Greaves failed to quote, show no evidence of such metabolism, as evidenced by excretion of label with the appropriate glucuronide metabolite.

Atrophy, telangiectasia, and rosacea have been reported after hydrocortisone. ${ }^{1314}$ Perioral dermatitis and rosacea were seen after hydrocortisone alone in $2 / 203^{15}$ and $2 / 28^{16}$ patients and when directly applied to the rash hydrocortisone was indistinguishable from more potent hydrocortisone ester known to cause rosacea in $7 / 28$ patients. The relative risk of hydrocortisone is likely to be greater than these and earlie studies $^{1718}$ would suggest from sole use of hydrocortisone, however, because $(a)$ over half the patients change their steroid; $(b)$ before the steroid aetiology was known a hydrocortisone induced rash would have been treated with a potent steroid and its initiation by hydrocortisone would therefore go unrecognised; $(c)$ topical hydrocortisone accounts only for $20-25 \%$ of steroid use and until recently was not used as a first line treatment.

Professor R Marks (31 August, p 600) says he found hydrocortisone to have "skin thinning ability of only $5-8 \%$ "- that is, to $92-95 \%$ of original thickness; but in fact after $42-44$ days he obtained a figure of 86 (9SD) $\%$ for hydrocortisone, which was no different from 84 (9)\% for betamethasone valerate. ${ }^{19}$ Professor Marks may well be right to prefer his beliefs to his data because there is no evidence that the early decrease in skin thickness of a few per cent that he has used and encouraged others to use has any relevance to the profound atrophy that occurs after corticosteroids, which we were able to attribute to collagen loss..$^{20-23}$

Because it is not possible to dissociate toxicity from pharmacological potency throughout the corticosteroid potency range I have argued that the question is not whether hydrocortisone is toxic but to what extent. Dr Du Vivier (31 August, p 601) dismisses this as an unwarranted extrapolation from potent to weak steroids. Does he think that in looking for the effects of low level irradiation we should ignore the effect of igh doses?

The US experience is quoted once again but remains irrelevant in the absence of formal studies including those directed at the effect of OTC hydrocortisone on fungal infections ${ }^{24}$; the more important aspect of the US experience is that OTC approval was given in 1979 despite the opposition to it by the American Academy of Dermatology. So Professor Marks should try asking his American colleagues what their reasons were just a few years ago.

He says the need for OTV hydrocortisone is because at any time $30-40 \%$ of the population has an "appreciable" rash, much of which is minor, short lived, and treatable. If that were true the whole population would get such a rash once a fortnight or three weeks and be applying their OTC hydrocortisone for one week in two or three of the rest of their lives. But supposing we accept these figures, where is the evidence of efficacy? It is, of course, Professor Marks's failure to get a grip on the definition of need and response in relation to diagnosis and clinical course of disease that allows his continued muddle about the difference between the laudable 
principle of self medication and the disastrous laissezfaire of drug abuse.

If the proponents have no appeal to our intellect what of Dr Rosenberg's appeal to our pockets (31 August, p 601)? While it is impossible to draw parallels between our system and one which charges by the millimetre for excised skin tumours, it does emphasise the uncomfortable and disturbing commercial undertone to this debate, because the pressure for OTC licensing seems arise not just from a defined patient need and proved response but also from the logic of industrial profit.

Finally, there is Professor Greaves's serious suggestion that "the onus is clearly on the opponents to provide evidence why hydrocortisone should not be introduced for OTC use.' The onus of proof is, and must remain, with those who introduce a drug, a new route of administration, or dosage. They must provide evidence of need, effect, and safety; and, of course, it is because they can do none of these that they wish to shift the responsibility.

Now that all the OTC pennants are fluttering side by side in the academic breeze we can see how threadbare they are, despite their gaudy colours. After such a show surely it is inconceivable that any regulatory body in the UK can possibly approve OTC licensing of topical hydrocortisone or any other corticosteroid.

SAM SHUSTER

Department of Dermatology,

University of Newcastle upon Tyne

Bulloch S. OTC hydrocortisone. Pharmaceut $\mathcal{F}$ 1985; Jul 20 70-1.

2 Schlagel CA, Sanborn EC. The weight of topical preparation required for total and partial body inunction. $\mathcal{F}$ Invest Dermatol 1964;42:253-6.

3 Feldmann RJ, Maibach HI. Regional variation in percutaneous penetration of ${ }^{14} \mathrm{C}$ cortisol in man. $\mathcal{F}$ Invest Dermatol 1967;48 181-3.

4 Feldmann RJ, Maibach HI. Penetration of ${ }^{14} \mathrm{C}$ hydrocortisone through normal skin. Arch Dermatol 1965;91:661-6.

5 Wester RC, Maibach HI. Relationship of topical dose and percutaneous absorption in rhesus monkey and man. $\mathcal{F}$ Inves Dercutaneous absorption in $1976 ; 67: 518-20$.

6 Wester RC, Noonan PK, Maibach HI. Percutaneous absorption of hydrocortisone increases with long-term administration. Arch Dermatol 1980;116:186-8.

7 Feinblatt BI, Aceto T, Beckhorn G, Bruck E. Percutaneous absorption of hydrocortisone in children. Am $\mathcal{F}$ Dis Child 1966;112:218-24.

8 Fanconi von G. Hemmung des Wachstums bei einem Sauglin durch die $\mathrm{zu}$ intensive Anwendung einer 1\%igen Hydrocortisonalbe aud des Haut bie generalisiertem Ekzem. Helo Pediat Acta 1962;17:267-8.

9 Hosking GP, Elliston $\mathrm{H}$. Benign intracranial hypertension in child with eczema treated with topical steroids. $\mathrm{Br} \mathrm{Med} \mathcal{J}$ 1978;i:550-1.

10 Fleischmajer R. The lack of systemic hydrocortisone effects after massive and prolonged external applications. $\mathcal{F}$ Invest Dermatol 1961;36:11-6.

11 Shuster S, Williams IA. Pituitary and adrenal function during administration of small doses of corticosteroids. Lancet 1961; ii:674-8.

12 Greaves MS. The in vivo catabolism of cortisol by human skin. $\mathcal{f}$ Invest Dermatol 1971;57:100-7.

13 Stevanovic DV. Corticosteroid-induced atrophy of the skin with telangiecstasia. Br $\mathcal{F}$ Dermatol 1972;87:548-56.

14 Guin JD. Complications of topical hydrocortisone. 7 Am Acad Dermatol 1981;4:417-22.

15 Wilkinson DS, Kirton V, Wilkinson JD. Perioral dermatitis: 12 year review. Br f Dermatol 1979;101:245-57.

16 Sneddon I. A trial of hydrocortisone butyrate in the treatment of rosacea and perioral dermatitis. Br $\mathcal{O}$ Dermatol 1973;89. 505-14

17 Sneddon IB. Adverse effects of topical fluorinated corticosteroids in rosacea. Br Med f 1969;i:671-3.

18 Sneddon I. Perioral dermatitis. Br 7 Dermatol 1972;87:430-4.

19 Tan CY, Marks R, Payne P. Comparison of xeroradiographic and ultrasound detection of corticosteroid induced derma thinning. I Invest Dermatol 1981;76:126-8.

20 Scarborough H, Shuster S. Corticosteroid purpura. Lance $1960 ; \mathrm{i}: 93-4$

21 Shuster S, Scarborough H. Senile purpura. Q J Med 1961;30 33-44.

22 Shuster S, Raffle EJ, Bottoms E. Skin collagen in rheumatoid arthritis and the effects of corticosteroids. Lancet 1967; 525-7.

23 Black MM, Shuster S, Bottoms E. Skin collagen and thicknes in Cushing's syndrome. Arch Derm Forsch 1973;246:365-8.

24 Birchall M. OTC hydrocortisone. Pharmaceut $\mathcal{F}$ 1985; May 11:581-2.

\section{Deaths from peptic ulceration}

SIR,-II agree with the message of Mr T V Taylor's review (7 September, p 653) that we cannot be complacent about peptic ulceration. In 1963 Krause showed, that $80 \%$ of patients with duodenal ulcer suffered a "serious course" when followed for three or more decades. Admittedly, much of the "serious course" was attributable to the fact that about $60 \%$ of the patients underwent surgical treatment for their ulcer disease. Gastric surgery represents a major cause of death of patients with ulcer disease ${ }^{2}$ and all gastric operations carry a mortality (depending on the type of operation and on the state of the patient, surgeon, anaesthetist, etc.

To quote reported mortality and morbidity values is somewhat misleading, because most surgeons do not record their results and most patients cannot chose to undergo surgical treatment by superspecialists. To 1981 (the last values which have available) the overall mortality for ulcer surgery in Scotland had remained quite steady during a decade at about $4 \%$ with mortality for elective operations of about $3 \%$. As for morbidity after operations for ulcers, most reported studies show Visick grade 3 or 4 results in $10-20 \%$ of individuals (when even Visick grade 2 results would not be acceptable during drug treatment). Serious postoperative problems are, of course, irreversible and very difficult to treat medically, so that "remedial" operations may become necessary. Recurrence rates after highly selective vagotomy have been as high as $30 \%^{3}$ and these values obscure the fact that surgeons do not routinely re-examine their patients endoscopically. When routine repeat endoscopy has been performed about $50 \%$ of the recurrences have been found to be asymptomatic.

Long term, continuous treatment with drugs does not have any calculable mortality in anybody's hands. The only important morbidity results from "breakthrough" reulceration, but the reulceration is clinically benign and asymptomatic in most patients $s^{5}$ and complications are extremely rare However, Mr Taylor has, I think, misinterpreted the recurrence data. There is not progressive and cumulative involvement of patients over the course of years; instead recurrence seems to affect a limited ulcer prone population, perhaps those who smoke or require greater than standard doses of drugs for maintenance treatment. True, most patients relapse after treatment is discontinued, even after five years of continuous therapy. We do not yet know whether the tendency to recur will decrease after 10 or 20 years of continuous therapy, because the matter has not yet been studied. It may be that treatment of ulcer disease will have to be life long-but so what, if the treatment is safe and satisfactory, as that provided by currently available $\mathrm{H}_{2}$ receptor antagonists is?

I tell my patients that "a pill a day keeps the surgeon away"-which makes both them, and myself, happy.

Ninewells Hospital

K G WORMSLEY

Krause U. Long-term results of medical and surgical treatment peptic ulcer. Acta Chir Scand 1963;125(suppl 310):1-11.

2 Boyd EJS, Wormsley KG. Natural history of duodenal ulcer Survey of Digestive Diseases (in press).

3 Madsen $P$, Kronborg $O$. Recurrent ulcer $51 / 2-8$ years after highly selective vagotomy without drainage and selective vagotom with pyloroplasty. Scand F Gastroenterol 1980;15:193-9.

4 Mühe E, Schick A, Rösch W. Selektive proximale Vagotomie ohn Drainage beim unkomplizierten Duodenalulkus. Fortschr Me 1979;97:2195-9.

5 Boyd EJS, Wilson JA, Wormsley KG. Safety of ranitidine maintenance treatment of duodenal ulcer. Scand f Gastroenterol $1984 ; 19: 394-400$

SIR,-Mr T V Taylor (7 September, p 653) bases his well argued case for elective surgical treatmen of peptic ulcer on the supposition that patients with peptic ulcer in their 40s will become the patients who perforate or bleed from ulcers in their $60 \mathrm{~s}$ and $70 \mathrm{~s}$. This supposition ignores the fact that many of the serious complications of peptic ulcer now occur in patients with no history of chronic ulceration. In a recent survey in Oxford we showed that two thirds of patients suffering a perforated peptic ulcer either had no previous symptoms or had experienced dyspepsia for less than three months before perforation.' This finding contrasts with those of earlier series in which most perforations followed chronic peptic ulceration. ${ }^{23}$

There has been a reduction in the overall mortality from perforated peptic ulcer, the rate falling from $20 \%$ in the early $60 \mathrm{~s}^{4}$ to $13 \%$ in 1977 82. ${ }^{1}$ This reduction in mortality has occurred despite the increasing age at which perforation tends to occur. Over 18 years in Oxford the mean age of patients presenting with perforation of a peptic ulcer increased from 54.8 to 60.9 years. There has been a marked decline in overall incidence of perforated peptic ulcer ${ }^{156}$ with age specific ulcer perforation rates showing a dramatic fall in the younger age groups while in the elderly they have fallen only slightly or even increased.?

Upper gastrointestinal haemorrhage, the other major complication of peptic ulceration, has increased in incidence by $25 \%$ in Oxford over the past 20 years. $^{8}$ This increase has occurred exclusively in patients over the age of 60 years and is in marked contrast to the substantial decline in overall incidence of symptomatic peptic ulcer.

These observations suggest that patients with chronic peptic ulceration no longer account for most cases of perforated or bleeding peptic ulcer in the elderly. Early surgery for symptomatic peptic ulcers cannot therefore be expected to produce the great saving in life which $\mathrm{Mr}$ Taylor predicts.

\section{R M WATKINS}

Surgical Unit,

London SWIP 2AP

JaCK Collin

Nuffield Department of Surgery,

John Radcliffe Hospital,

Oxford OX3 9DU

Watkins RM, Dennison AR, Collin J. What has happened to perforated peptic ulcer? Br $\mathcal{J}$ Surg 1984;71:774-6.

2 Cassell P. The prognosis of perforated acute duodenal ulcer. Gut $1969 ; 10: 572-4$

Kay PH, Moore KTH, Clark RG. The treatment of perforated duodenal ulcer. Br 7 Surg 1978;65:801-3.

4 Sanders R. Incidence of perforated duodenal and gastric ulcer in Oxford. Gut 1967;8:58-63.

Dark JH, MacArthur K. Perforated peptic ulcer in south-wes Scotland. I R Coll Surg Edinb 1983;28:19-23.

Hendry WS, Valerio D, Kyle J. Perforated peptic ulcer in north east Scotland. $\mathcal{A} R$ Coll Surg Edinb 1984;29:69-72.

Coggon D, Lambert P, Langman MJS. 20 years of hospital admission for peptic ulcer in England and Wales. Lancet $1981 ;$ i: $1302-4$.

Berry AR, Collin J, Frostick SP, Dudley NE, Morris PJ. Upper gastrointestinal haemorrhage in Oxford. A prospective study. IR Coll Surg Edinb 1984;29:134-8.

\section{Antihypertensive treatment in pregnancy}

SIR,-Dr E D M Gallery and others (31 August, $p$ 563) presume that all women in their study will benefit from antihypertensive therapy and so do not use a control group. The references they quote in support of this assumption nearly all refer to the treatment of severe hypertension in pregnancy, and Redman et al suggest that chronic hypertension in the second half of pregnancy does not require medication until it reaches $170 / 110 \mathrm{~mm}$ Hg. ${ }^{2}$ Dr Gallery and colleagues, however, treat patients with a minimum diastolic pressure of 90 $\mathrm{mm} \mathrm{Hg}$.

The data for mild and moderate hypertension 